ALMADA, Carlos de Lemos. (2016) Derivative Analysis and Serial Music: the Theme of Schoenberg's Orchestral Variations Op.31. Per Musi. Ed. by Fausto Borém, Eduardo Rosse and Débora Borburema. Belo Horizonte: UFMG, n.33, p.1-24.

DOI: $10.1590 /$ permusi20163301

SCIENTIFIC ARTICLE

\title{
Derivative Analysis and Serial Music: the Theme of Schoenberg's Orchestral Variations Op.31
}

\author{
Análise derivativa e a música serial: \\ O tema das Variações para Orquestra op.31 de Schoenberg
}

\section{Carlos de Lemos Almada}

Universidade Federal do Rio de Janeiro, Rio de Janeiro, Rio de Janeiro, Brasil. carlosalmada@musica.ufrj.br

Abstract: The main objective of this paper is to investigate the derivative relations between the constituent elements of the theme of Arnold Schoenberg's Orchestral Variations Op.31 and its source of basic material or Grundgestalt, a theoretical principle elaborated by the composer. After a bibliographical revision concerned with the origins and motivations for the formulation of the concept, the paper discusses the problematic issue of the presence of thematic development in Schoenberg's serial music, taking as reference analyzes by some authors (RUFER, 1954; BOSS, 1992; HAIMO, 1997; TARUSKIN, 2010). It is also proposed that the Grundgestalt of a twelvetone piece can be manifested according to two levels, abstract and concrete, which adjusts to the analytical methodology adopted in this study, described in a specific section of the paper. The results obtained reveal an extraordinarily organic and economic thematic construction.

Keywords : derivative analysis; Grundgestalt; developing variation in serial music; Arnold Schoenberg's serial music.

Resumo: Este artigo tem como objetivo principal investigar as relações de derivação entre os elementos componentes do tema das Variações para Orquestra op.31 de Arnold Schoenberg) e sua fonte de material básico, ou Grundgestalt, conceito teórico elaborado pelo próprio compositor. A partir de uma revisão bibliográfica considerando as origens e motivações para a formulação do conceito, é discutida a questão sobre a presença de desenvolvimento temático em obras seriais de Schoenberg, tomando como referência análises realizadas por alguns autores (RUFER, 1954; BOSS, 1992; HAIMO, 1997; TARUSKIN, 2010). Propõe-se ainda a que a Grundgestalt de uma obra serial possa se manifestar em dois níveis distintos, porém associados - abstrato e concreto, o que se ajusta à metodologia analítica adotada neste estudo, sumarizada em 
uma seção específica do artigo. Os resultados obtidos revelam uma construção temática extraordinariamente orgânica e econômica.

Palavras-chave: análise derivativa; Grundgestalt; variação progressiva em música serial; música serial de Arnold Schoenberg.

Data de recebimento: 03/12/2015.

Data de aprovação final: 18/03/2016.

\section{1 - Introduction}

This paper is part of a broad research project which aims to systematically study musical variation under analytical and compositional perspectives, theoretically grounded on the principles of developing variation and Grundgestalt, both elaborated by Arnold Schoenberg (1874-1951). The present case addresses a specific branch of the former approach, named thematic derivative analysis (henceforward, TDA), an original methodology developed and consolidated during the research. TDA is intended to investigate if the structure of a theme (or a group of themes) of a given musical work could be explained under the bias of gradual and progressive transformations (i.e., through developing variation) from a reduced set of basic ideas (the Grundgestalt). This conception implies an organic and economic construction, and can be historically, and stylistically associated to the formalist-organicist AustroGerman tradition, represented especially by Mozart, Beethoven, Brahms, Schoenberg, and Berg. This study presents the first application of TDA to a serial work, through the exam of the derivative structure of the theme of Schoenberg's Orchestral Variations Op.31. The main objective of this approach is to investigate whether the method may be also suitable for non-tonal music, a perspective supported by analyzes of other authors.

\section{2 - The principles of developing variation and Grundgestalt}

Elaborated by Arnold Schoenberg, the correlated principles of developing variation and Grundgestalt may be considered the main and far-reaching of his contributions for 
compositional theory. Both can be associated to the trend of Organicism, a conception for musical creation that strongly influenced romantic Austro-German composers, especially Mozart, Beethoven and Brahms (MEYER, 1989, p.189-200). The latter was considered by Schoenberg as the most talented master of thematic development (SCHOENBERG, 1984, p.398-441) and this aspect was certainly one of the main factors that influenced the consolidation of his own compositional style, based essentially in a kind of synthesis of Wagnerian and Brahmsian attributes (FRISCH, 1993, p.xv-xvi). In fact, the employment of derivative processes in the construction of his musical works is perhaps the most distinctive trait of Schoenberg's creative personality (HAIMO, 1997, p.352), present not only in his tonal phase (1893-1908). As Stephen Collison argued, the concept of Grundgestalt (normally translated as "basic format") was

\footnotetext{
formulated by Schoenberg in 1919, during the early stages of his development of the twelve-tone principle ... to demonstrate a continuity between the compositional processes of the classicalromantic Viennese school and his own music, be it tonal, atonal or twelve-tone. COLLISON (1994, p.20)
}

Therefore, contrary to the common sense, the theoretical formalization of organic musical construction by Schoenberg was primarily intended not to explain developmental thematic procedures adopted by Brahms (among others) and, of course, by himself in his tonal phase, but rather to reinforce that his recent (atonal/pre-serial) works were still built with the same "receipt" that characterize his creative style: the gradual, economic, pervasive and progressive transformation from a limited group of basic ideas.

Josef Rufer, one of Schoenberg's pupils, wrote a book about the twelve-tone method based on his own classroom notes, Schoenberg writings, and correspondence with his master. Rufer defines Grundgestalt initially as a kind of intermediary stage between a motive and a theme (RUFER, 1954, p.viii). In the same passage, the author stresses the necessity of distinguishing clearly the concepts of Grundreihe (basic row) and Grundgestalt: 
The latter is a wide musical concept; the former belongs to twelve-tone music and is part of the latter.(...) in Schoenberg's music the Grundgestalt as the 'first creative thougth' is of primary importance, but not the series, which is derived from the Grundgestalt. (op.cit., p.ix)

One can deduce from both definitions that a Grundgestalt of a given Schoenbergian serial piece may operate considering two structural perspectives: (1) on a surface level, with the Grundgestalt being formatted as a concrete musical material, like the "intermediary stage" mentioned by Rufer. This concrete Grundgestalt corresponds ultimately to the "conventional" conception of this principle, normally associated to tonal, organic-constructed music (composed, for example, by Beethoven or Brahms); and (2) on a basic level. In this context, the Grundgestalt, the "first creative thought" of a composition, can be viewed as an abstract idea (presumably associated to a specific intervallic configuration), from which the twelve-tone series is derived. Both kinds of Grundgestalten will be considered in this study, being identified as $\mathrm{G}_{\mathrm{s}}$ (superficial) and $\mathrm{Gb}$ (basic).

Among innumerable definitions already written about the principle of developing variation, the one proposed by Ethan Haimo seems to be the most complete and, at same time, sufficiently generalizing to encompass Schoenberg serial procedures:

\footnotetext{
Developing variation is a special category of variation technique, one that implies a teleological process. As a result, later events - even markedly contrasting ones - can be understood as originate from, or grow out of, changes that were made in the repetitions of early musical unities. Therefore, true developing variation can be distinguished from purely local varied repetitions that have no developmental consequences. Developing variation offers the possibility of forwards motion, permitting the creation of new or contrasting (but still related) ideas, while local variation affects only the passage in question.
}

In other terms, developing variation can be viewed as a powerful process, which is responsible not only for producing musical material with several degrees of resemblance with the basic idea (considering its two levels), but also capable to organize this material according to the structural functions of the formal sections of a given musical piece.

Probably due to a general misconception that tonality is a sine qua non condition for organic musical construction, there are relatively few academic studies devoted to 
ALMADA, Carlos de Lemos. (2016) Derivative Analysis and Serial Music: the Theme of Schoenberg's Orchestral Variations Op.31. Per Musi. Ed. by Fausto Borém, Eduardo Rosse and Débora Borburema. Belo Horizonte: UFMG, n.33, p.1-24.

derivative analysis of the post-tonal repertoire. However, there is not necessarily a direct relation between the material and the manner with which it is molded. In fact, Schoenberg's compositional style (no matter which of his phases or the adopted melodic-harmonic idiom is considered) can be summarized as based on extensive motivic-thematic transformational treatment. Evidently, the absence of the familiar environment established by the action of the functional forces inherent to tonality can represent actual difficulties for the analyst. Formal boundaries in non-tonal contexts are frequently blurred (or even disappear), since the relative stability caused by local and global cadential points is virtually suspended. In other words, this sort of music lacks unequivocal referential points for a hierarchical structural organization.

In spite of this, some authors have proposed convincing analytical approaches addressing the derivative thematic treatment present in Schoenberg's late tonal, atonal, and serial music, which have become important references for this paper. The first of these analyses was made by the composer himself, encompassing two of his pieces: the atonal Four Orchestral Songs Op.22 (composed in 1913-16) and the theme from the Orchestral Variations Op.31 (concluded in 1928), which is precisely the focus of the present study. Both were originally presented in 1931-32 as broadcast lectures at the Frankfurt Radio, being later transcribed and published. ${ }^{1}$ Intended primarily to present his new music to the common public (although relatively well informed and interested), the analyzes of these pieces are comprehensibly not so deeply and systematically as it is nowadays normally required of an academic study. Moreover, as it is frequently pointed by modern commentators, ${ }^{2}$ Schoenberg argumentation sometimes is vague, elliptic and even arbitrary while identifying and labeling motives and their derivations in his analyzes. Anyway, these studies are rare and extraordinary opportunities to examine Schoenberg's modus operandi concerning the development of musical ideas. In this aspect, Jack Boss formalized a methodology for systematical motivic-transformational analysis and applied it to the examples presented by

\footnotetext{
1 The typescript of the two lectures can be read in the site of the Arnold Schoenberg Center of Vienna (available in: http://schoenberg.at/index.php/de/archiv/texte).

2 See, for example, EPSTEIN (1980, p.17), LEIGH (1998, p.i) and CONLON (2009, p.116), among others.
} 
ALMADA, Carlos de Lemos. (2016) Derivative Analysis and Serial Music: the Theme of Schoenberg's Orchestral Variations Op.31. Per Musi. Ed. by Fausto Borém, Eduardo Rosse and Débora Borburema. Belo Horizonte: UFMG, n.33, p.1-24.

Schoenberg in the Op.22 lecture (BOSS, 1992), using a mathematical approach, in some aspects similar to TDA (described in the next section).

Just one year after his master's death, Josef Rufer published his book on the twelvetone method (RUFER, 1952/1954). Besides a detailed explanation about its postulates and the multitude of compositional possibilities extracted from analyzes of a vast group of Schoenberg's serial works, the author presents an original perspective about the correlations between the Grundgestalt (considering implicitly both its levels, as previously mentioned) and the manners used for elaboration and manipulation of the series. After demonstrating his own methodology in an analysis of Beethoven's Piano Sonata 0p.10/1, Rufer proposes to extend its application to twelve-tone music, stressing the fact that Beethovenian and Schoenbergian thematic treatment, apart the differences of their respective harmonic idioms, are essentially equivalent (RUFER, 1954, p.38-45; see also p.55-78).

In a detailed prospect on Western music from 1900-1950, Richard Taruskin devotes a long chapter to the analysis of representative serial works by Schoenberg, Berg and Webern (TARUSKIN, 2010, p.675-741). The author especially emphasizes the relations between the concept of Grundgestalt and the choice of the intervallic structures for the pieces' respective rows, as well as the various manners with which their music are formatted through use of techniques for serial manipulation.

Ethan HAIMO (1997) discusses the employment of developing variation techniques in the instrumental introduction of Scene 2 (Act 1) of the opera Moses and Aaron. His focus addresses the gradual transformation suffered by a basic motivic cell $\left(\mathrm{a} \mathrm{G}_{\mathrm{s}}\right.$, in this case, according to our terminology) resulting in a multitude of derived formulations. Haimo is especially interested in the ways with which Schoenberg manipulated the serial forms in order to mold the developmental processes to his compositional intentions. Impressed by the analysis results, which denotes a notable flexibility in the use of the twelve-tone technique by the composer, and a clear priority of the motivic-thematic treatment over the method protocol, the author concludes that 


\begin{abstract}
Serial ordering and developing variation might seem incompatible concepts, the one suggesting strict order, the other implying spontaneity and freedom. In Schoenberg's twelve-tone mature works serial ordering and developing variation are not in conflict. Nor do they mere coexist. Rather, they complement one another, depending on one another for their very viability (HAIMO, 1997, p.363)
\end{abstract}

In our understanding, the plainly conscious, and confident use of this sort of malleability for expression of ideas represents an important mark of Schoenberg's trajectory: a long-expected reconciliation between his most essential compositional characteristic, based on extensive motivic developmental construction (someway neglected since the abandonment of tonality), and the needs and constraints of the twelve-tone idiom.

Being composed just some years before Moses and Aaron, the Orchestral Variations Op.31 denotes clearly a similar flexible serial construction in favor of a thematicoriented conception. ${ }^{3}$, The Op.31's theme results from a remarkable interaction between formal, serial and developing variation procedures, as it will be demonstrated on the fifth section of this paper.

\title{
3 - The thematic derivative analysis
}

The thematic derivative analysis (TDA) was originally conceived as a method for systematical examination of organic-constructed musical pieces. It was firstly applied to the analysis of the thematic structure of Schoenberg's First Chamber Symphony Op.9, and since then a number of other analyzes were made, encompassing different periods, works and composers. ${ }^{4}$

Compared to other similar analytical methods, TDA is based on a distinctive premise, namely, that the derivative process can be operated hypothetically on two levels:

\footnotetext{
${ }^{3}$ For a detailed analysis on Op.31' serial organization, see LEIBOWITZ (1997, p.11-219).

${ }^{4}$ See ALMADA (2011a-b; 2013a-b) and MAYR \& ALMADA (2014).
} 
concrete and abstract. While the former is concerned with, so to speak, conventional development, that is, based on transformation of "real" musical ideas, the latter needs further explanation. Variation on abstract level occurs based on a given abstracted musical structure. In thesis, any musical domain may be considered as referential for abstract development (dynamics, timbre, articulation, texture, etc.), but rhythmic and pitch sequences are certainly the most efficient candidates for analytical practical purposes. Derivative processes on abstract and concrete levels in TDA are labeled as developing variation, respectively, of first and second order.

The formalization of TDA is based on this assumption, namely, the duality of abstract/concrete levels. The main elements of the model can be briefly described as follows:

(a) The basic unity, the Grundgestalt (G) is normally segmented into motivic elements, named Grundgestalten-components (Gc's), labeled with bold capitals, as shown in Figure 1. G and Gc's are part of concrete level (evidently, G in this case corresponds to the $\mathrm{G}_{\mathrm{s}}$ class). The subsequent stages of the process occur on the abstract level;

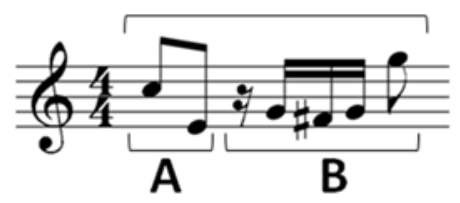

Figure 1: A hypothetical Grundgestalt and its two Gc's.

(b) Two abstracted sequences are obtained from each Gc: an intervallic and a rhythmic sequences (Figure 2). They are named Grundgestalten-abstractions (Ga's), and indentified with the same letter of the Ga of origin (in lowercase), the domain considered ("i" for the intervallic sequence, "r" for the rhythmic one), and their respective contents, notated as numeric strings. ${ }^{5} \mathrm{~A}$ Ga is represented

\footnotetext{
5 The numeric conventions adopted are the following: (a) for intervallic sequences: the integers represent quantities of semitones and the plus and minor signals correspond to the directions of the intervals (respectively, upward and downward); (b) for rhythmic sequences: the integers represent durations ( $1=16$ th note, $2=8$ th note, and so on), and the signals, the occurrence of onset $(+)$ or rest $(-)$.
} 
in the analysis in two complementary versions: in musical notation and in graphic format, with its identifier data inserted in a full-line rectangle;
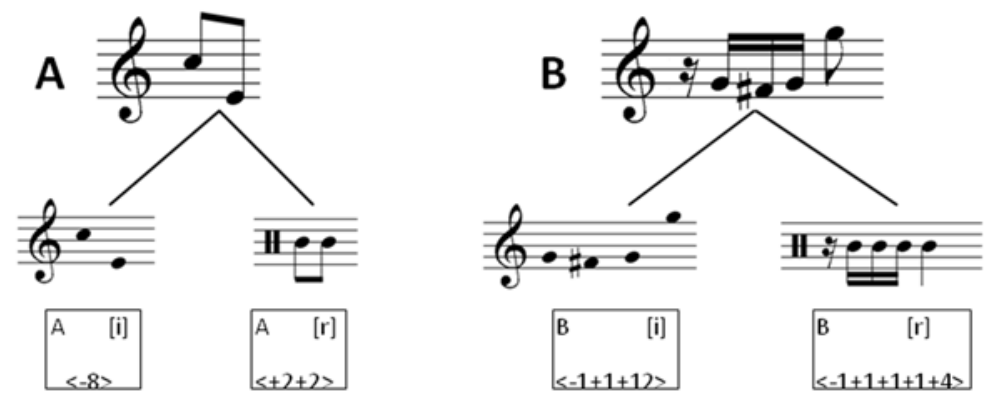

Figure 2: Ga's abstracted from the Gc's of Figure 1

(c) The Ga's are the referential elements for the phase of developing variation of first order (DV1). A Grundgestalt-variant (Gv) is obtained through application of a transformational operation (as, for example, inversion, augmentation, permutation, etc.) to a selected Ga. A Gv is labeled with the same letter (and domain) of the Ga from which it originates, being numbered according to the order and generation of its production, and graphically represented by a dashed-line rectangle (Figure 3). This process may be repeated over and over again, resulting in an indefinite number of generations of Ga's;

\section{(second generation)}
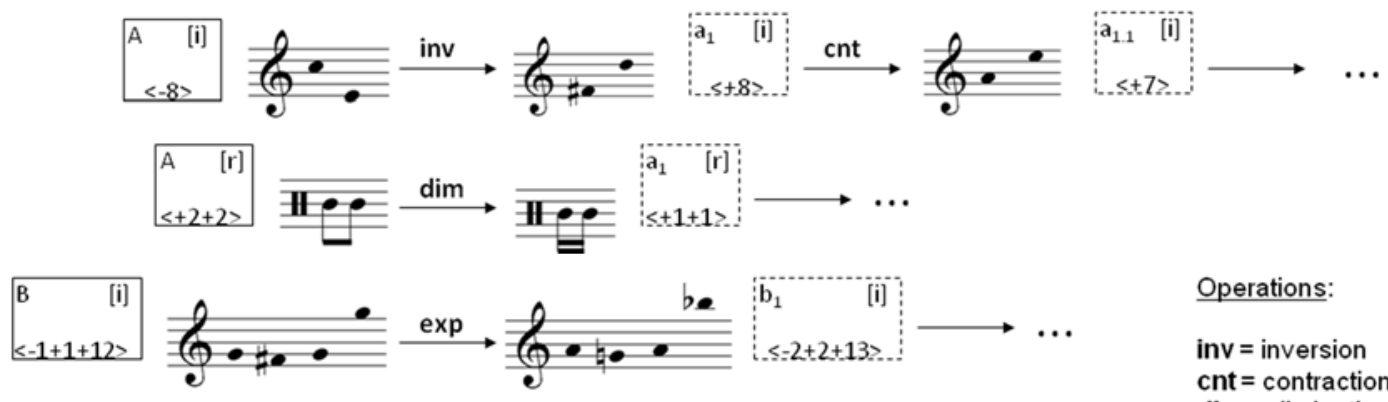

Operations:

inv $=$ inversion cnt $=$ contraction dim = diminution B $\quad[r]$
$k-1+1+1+1+4>$
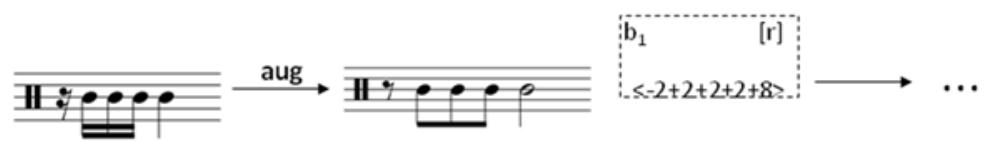

$\exp =\operatorname{expansion}$ aug $=$ augmentaion

Figure 3: Some possible Gv's resulted from transformation of Ga's of Figure $2 .^{6}$

\footnotetext{
${ }^{6}$ As it can be observed in Figure 3, intervallic variation does not consider transposition of the original sequence, just the transformations operated in its intervals.
} 
(d) A return to the concrete level is effected when intervallic and rhythmic Ga's are crossed over, yielding a "real" musical unity (as a kind of motive), classified as Pheno-variant (Pv). A Pv is identified with integers inserted in gray rectangles, according to their order of creation. Eventually, a Pv may become a referential form for production of further variants, through some sort of transformation (in this case, normally a free, non-canonic operation), which corresponds to the developing variation of second order procedures (DV2). These descendants are numbered according to their derivation, as shown in Figure 4.
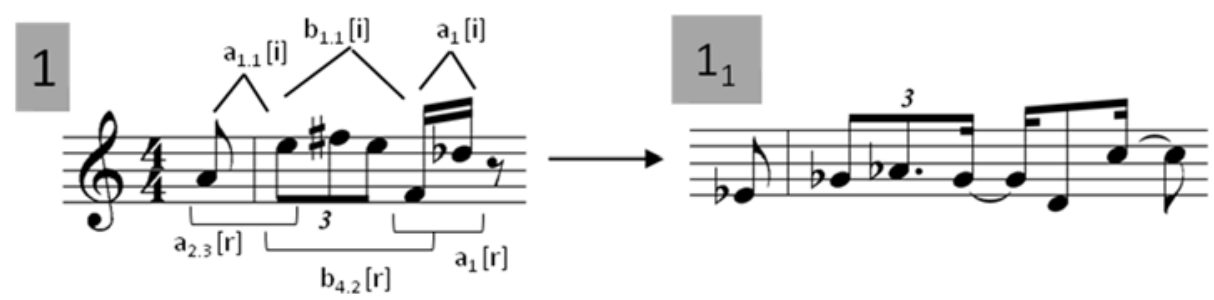

Figure 4: A hypothetical Pv (based on elaborations on the abstract forms Figures 2-3) and a possible descendant.

(e) Figure 5 summarizes the elements above presented. 


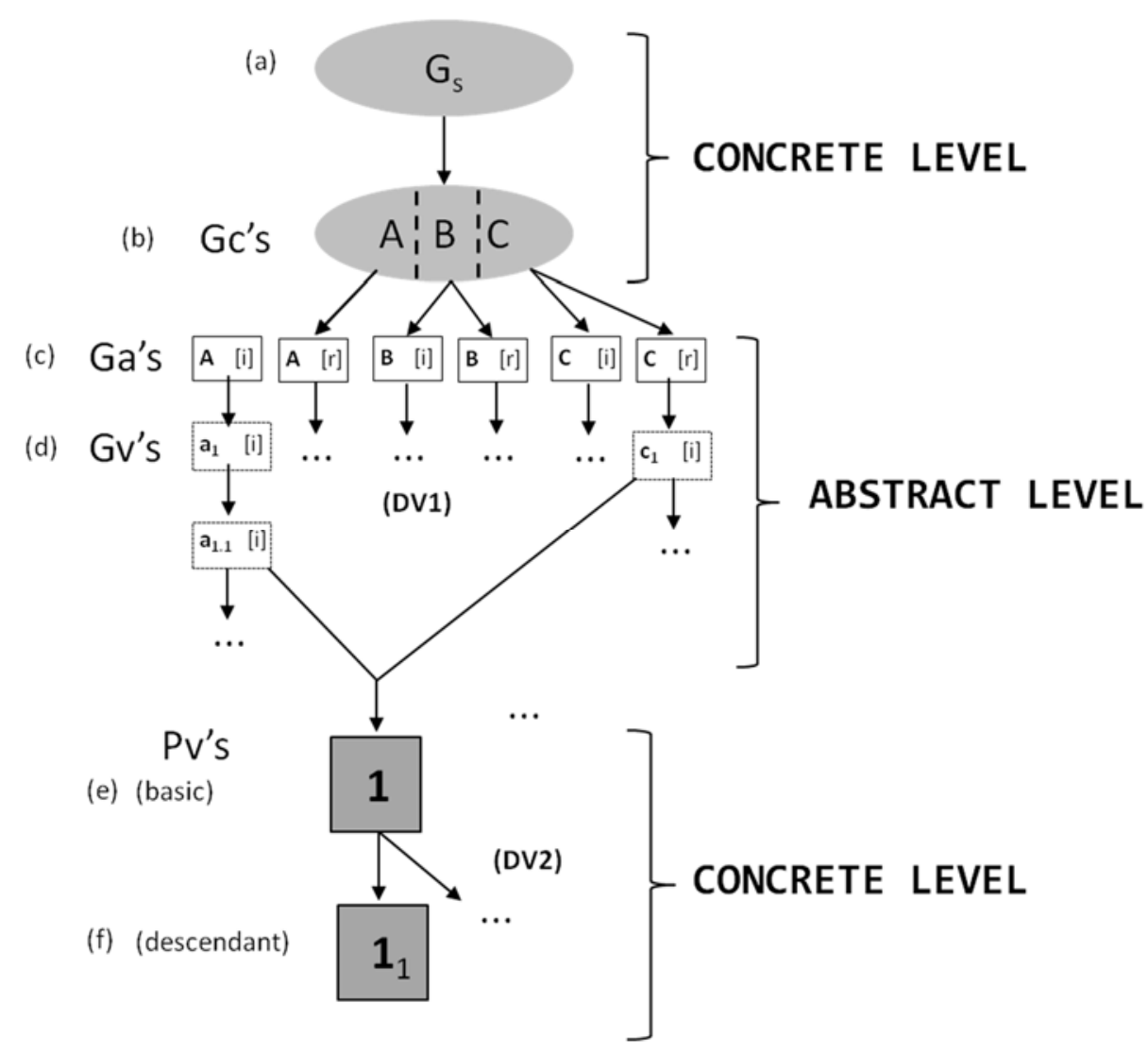

Figure 5: The stratified structure of TDA: (a) Grundgestalt; (b) Grundgestaltencomponents; (c) Grundgestalten-abstractions; (d) Grundgestalten-variants; (e) basic Pheno-variants; (e) descendant Pheno-variants.

\section{4 - The analysis of Schoenberg's Variations for Orchestra theme}

The Op.31's theme is presented by the cellos after a 33-bar orchestral introduction (with the first violin joining the line in the last 7 bars), being supported by a relatively simple, transparent homophonic texture formed by woodwinds, French horns, harp and contrabass.

Before beginning the derivative analysis, it is appropriate to examine the theme according to its serial and form structures, since both elements contribute to clarify certain of Schoenberg's choices for his developmental procedures. 


\section{1 - Serial structure}

The Op.31's row presents an ingenious construction based on the symmetrical properties of the tritone. As can be seen in Figure 6.a, two tritones (Bb-E / C\#-G) are strategically positioned in the first and second hexacords (order numbers 0-1 / 7-8).

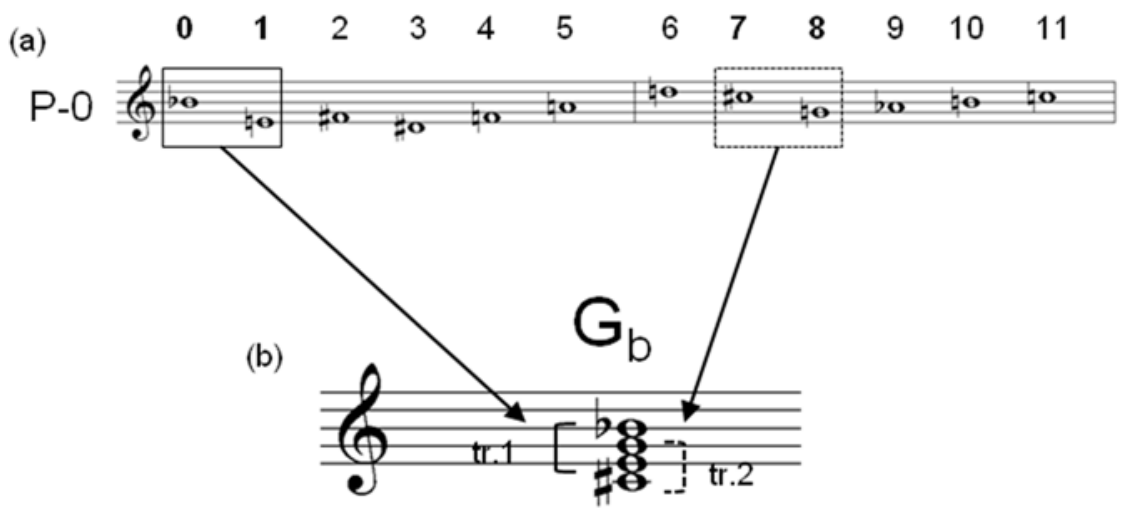

Figure 6: Schoenberg's Op.31: the row's primordial form (P-0).

As pointed by TARUSKIN (2010, p.706-707), the conjunction of both intervals (forming a circle of minor thirds or the "diminished-seventh chord") can be properly considered as the "basic shape" for the whole work, or its basic-level Grundgestalt (Gb), according to the present terminology (Figure 6.b).

Moreover, it is remarkable that Schoenberg preferentially uses in the piece a reduced number of serial forms for obtaining the pitch-structure (again according to the minorthird circle): P-0, P-3, P-6, P-9, I-0, I-3, I-6, I-9 (and their respective retrograde versions). This group forms what is designed by TARUSKIN (2010, p.689) as a "row complex", a kind of referential matrix which could be compared to a "tonic region". These forms share an important property: all of them maintain as invariant the tritones 1 and 2 (or, taking them as forming a unity, $\mathrm{G}_{\mathrm{b}}$ ) in the same positions (Figure 7). 


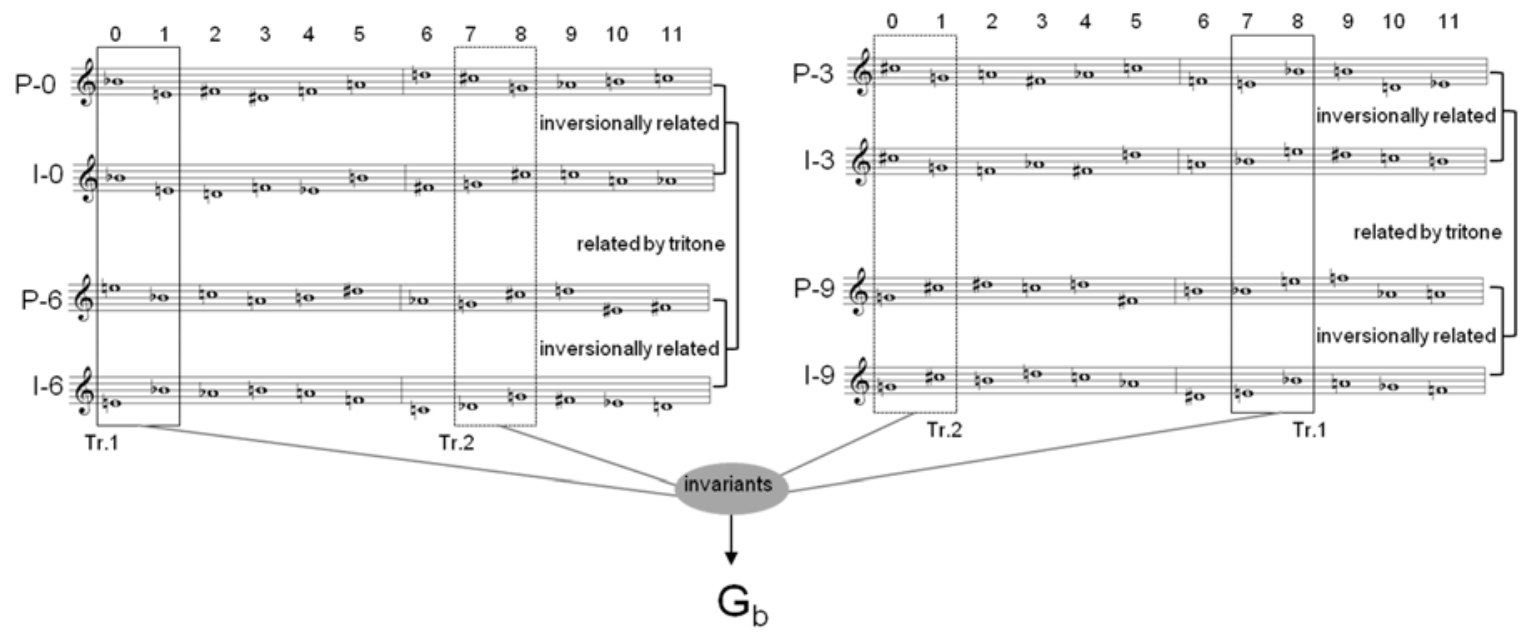

Figure 7: Schoenberg's Op.31: the row complex.

The theme's serial structure (Figure 8) is obtained from a subset of the row complex: P-0/R-0 and I-9/RI-9 (the remaining forms are employed in the accompaniment). Straight and dashed-line rectangles identify the presence of tritones 1 and 2 (as will be seen, their positions in some points of the melodic line are by no means arbitrary).

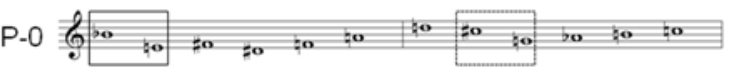
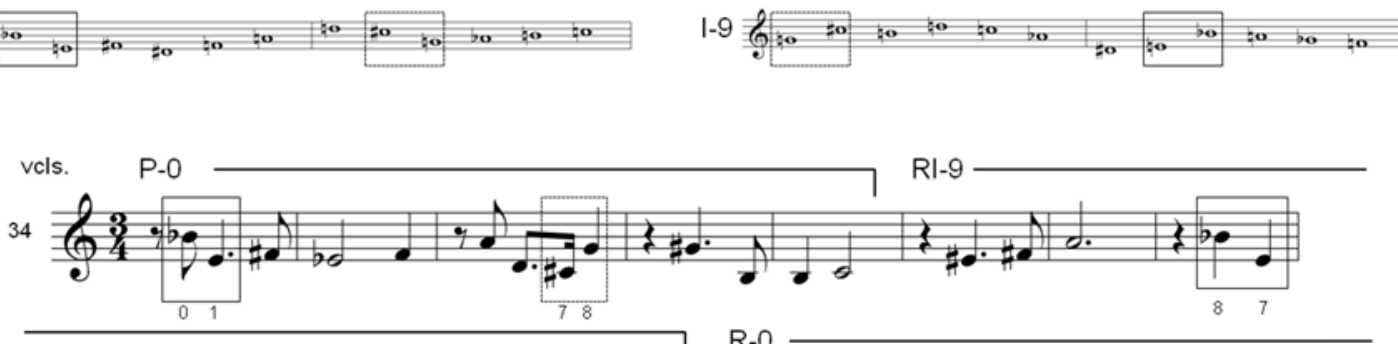

42
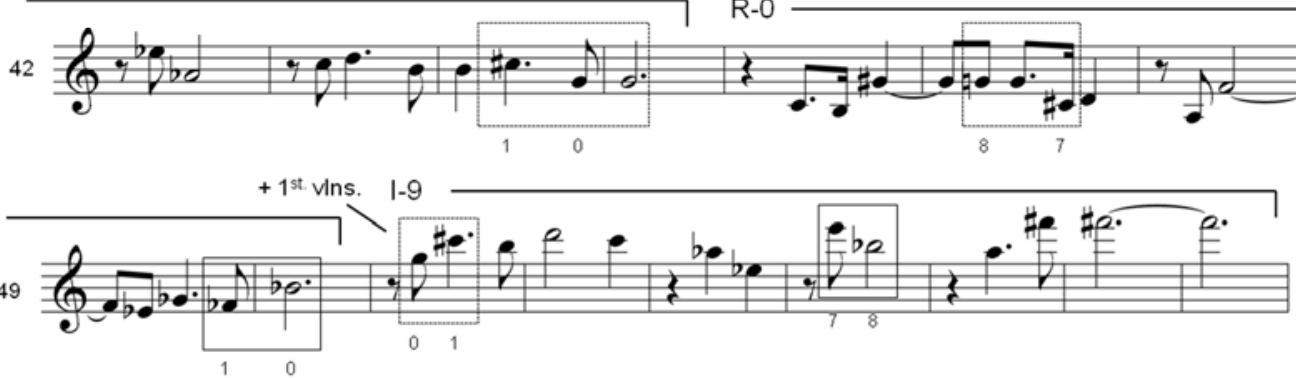

Figure 8: Schoenberg's Op.31 (mm.34-57): the theme's serial structure. 


\section{2 - Formal analysis}

The theme of the $0 p .31$ can be considered as an example of practical application of some abstract formal configurations described theoretically by Schoenberg in his book Fundamentals of musical composition (SCHOENBERG, 1990). As it was demonstrated in a previous study (ALMADA, 2009, p.37-39), the theme can be viewed on a broad level of organization as a "small ternary form" (a-b-a), with its main section $(a)$ built according to the model of the "period", subdivided into "antecedent" and "consequent" (Figure 9). The recapitulative section ( $a^{\prime}$ ) presents a resumed version of $a$, while the contrasting section $(b)$ is formatted as a simple "proposal-response" pattern. Both strategies correspond to Classical-Romantic procedures, as stated by Schoenberg (1990, p.119-126). Figure 9 proposes a stratified formal analysis of the theme, considering at most four levels of organization.
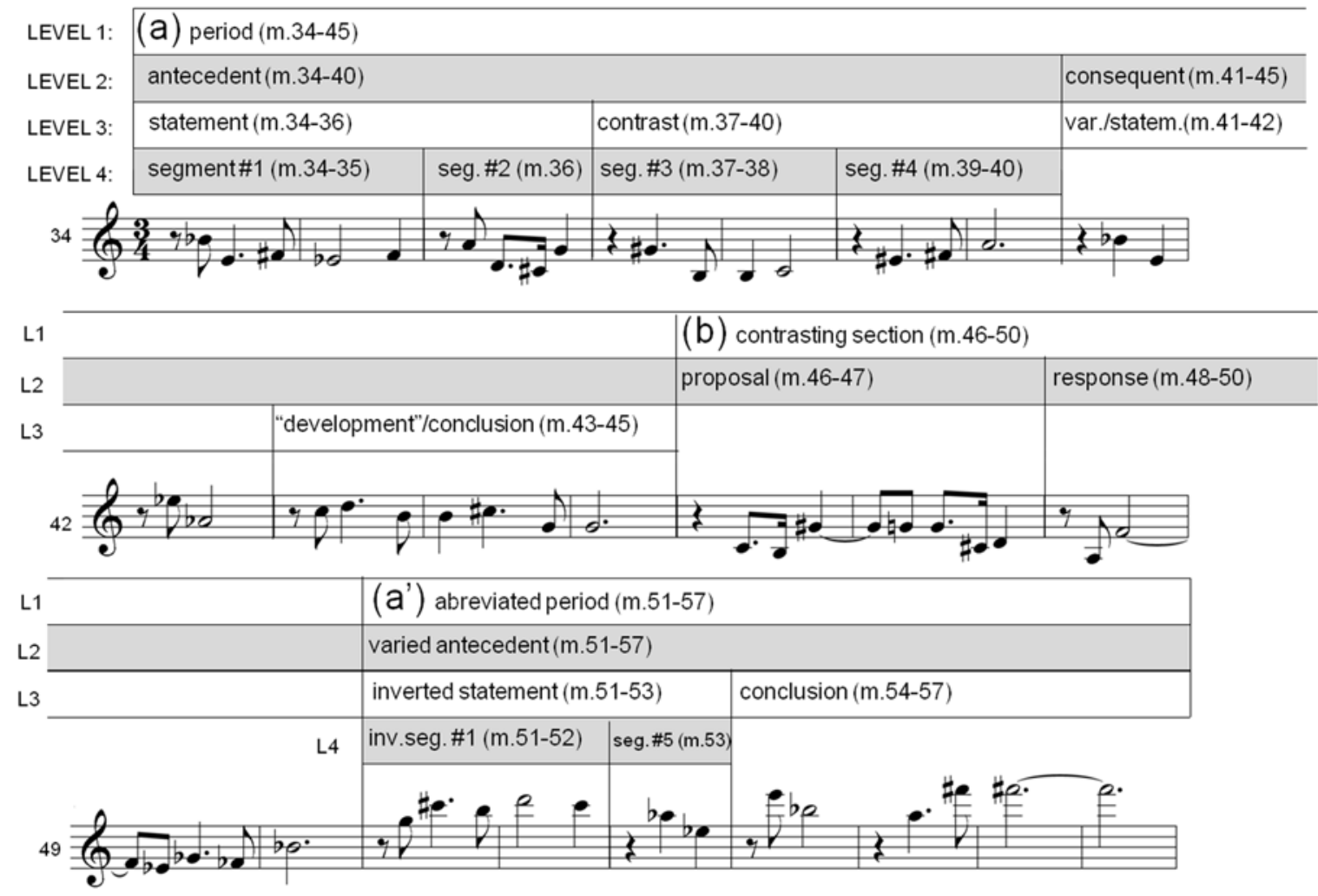

Figure 9: Schoenberg's Op.31 (mm.34-57): the theme's formal structure. 
A comparison between the serial and the formal structures (Figure 10.a-b) reveals an almost perfect match of the respective segmentation, with a unique exception, the passage of mm.39-40, labeled as "seg.\#4" in Figure 9. At first, the beginning of the serial form RI-9 at this point could suggest the occurrence of a relatively important formal boundary (i.e., considering level 1 or level 2, like the remaining changes of serial forms). However, the seg.\#4 functions as a mere subordinate subsection of the second part of the antecedent. Considering the notorious predilection of Schoenberg for clarity, symmetry and logic in the serial segmentation, this discrepancy may at first seem quite enigmatic. The central reason of this particular choice may be explained by the positions and functions attributed to some of the tritones 1 and 2 in the melodic line. As suggested in Figure 10.c, Schoenberg's intention was probably motivated by a need of expressing an adequate relation of similarity between the beginnings of the antecedent and the consequent, by maintaining the tritone 1 as an invariant, common element. Since it is produced by pitches of number 8-7 in RI-9, it was necessary to anticipate the entry of this serial form in two measures, with pitches 11-9 forming the last part of the antecedent. ${ }^{7}$ Anyway, as it was pointed by Ethan Haimo in his analysis, this case can be seen as a simple, but clear example of how Schoenberg subordinates the serial procedures to the needs of the motivic treatment.

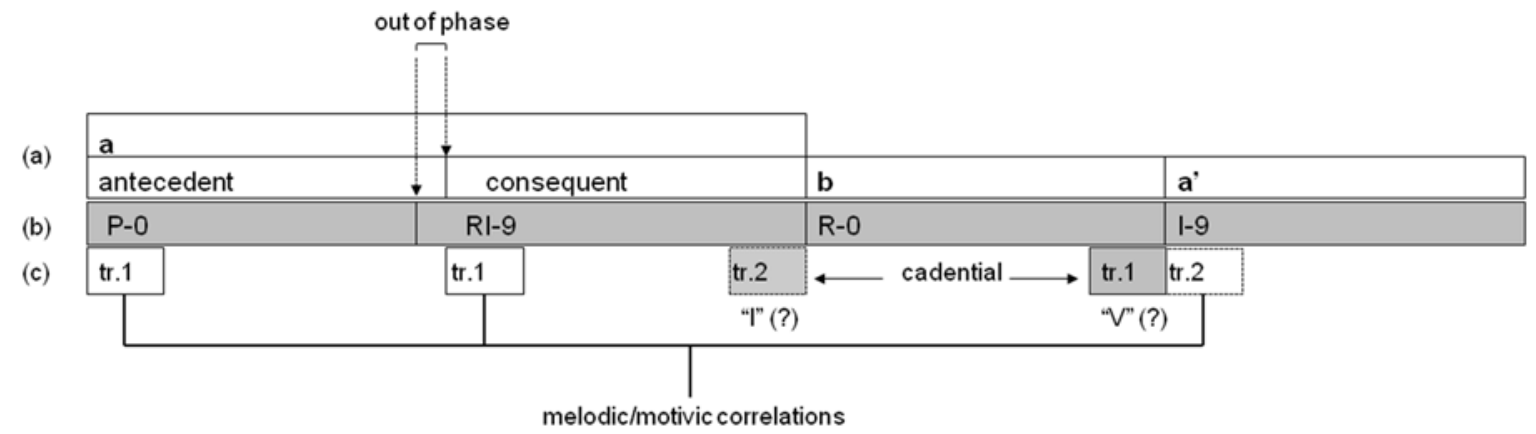

Figure 10: Schoenberg's $O p .31$ (mm.34-57): comparison between formal and serial structures.

\section{3 - Derivative structure}

\footnotetext{
${ }^{7}$ In addition to this motivic application, it is plausible to consider that the tritones positioned at the end of sections $a$ and $b$ (indicated by the shading rectangles in Figure 10.c) could exert a sort of harmonic function, analogous to the perfect and half tonal cadences.
} 
The application of TDA to the Op.31's theme starts with the proper identification of its "concrete" basic shape (more precisely, its Gs, the surface-level Grundgestalt), the source of material for organic construction. As shown in Figure 11.a, Gs is segmented into three overlapping Gc's (A, B and C). Figure 11.b presents the six Ga's abstracted from the three Gc's. It is noteworthy that the abstractions from $\mathbf{C}$ can be also explained as resulting from elaboration of previous forms (Figure 11.c). This is a meaningful fact, since it implies that the developing variation of first order is acting within the limits of the Grundgestalt.

(a)

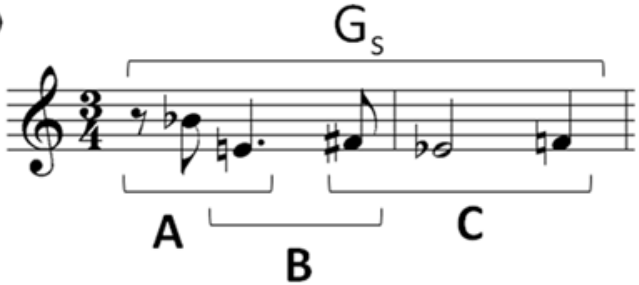

(b)

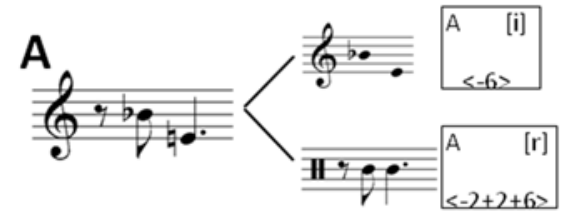

B
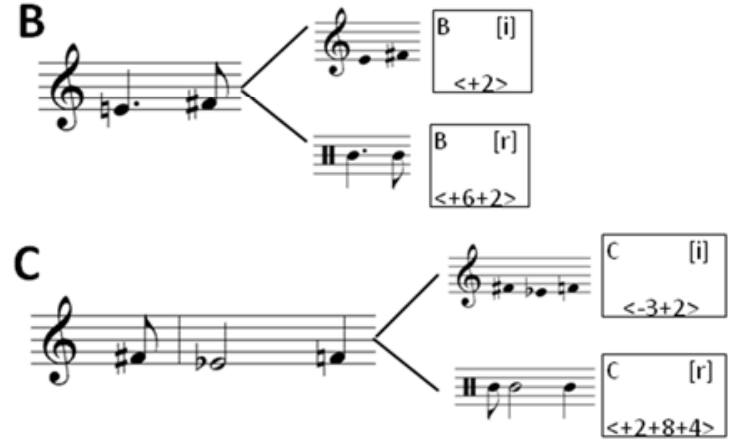

(c)

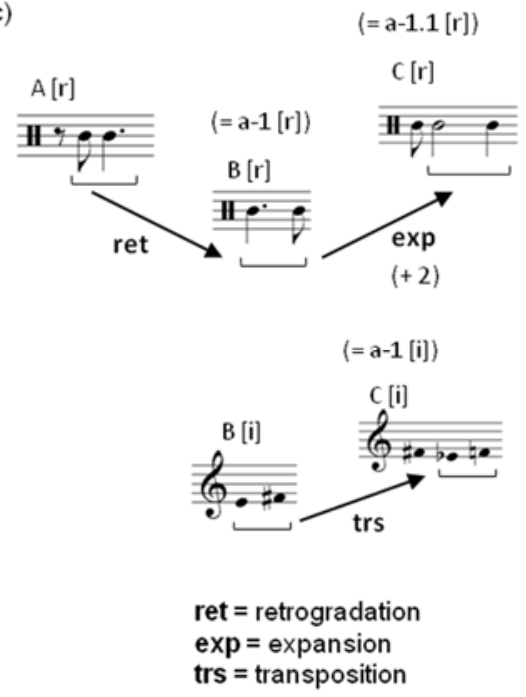

Figure 11: Schoenberg's Op.31: the Gs and Gc's A, B and C (a); Ga's A[i], A[r], B[i], $\mathbf{B}[\mathrm{r}], \mathbf{C}[\mathrm{i}]$ and $\mathbf{C}[\mathrm{r}](\mathrm{b})$; possible derivation of $\mathbf{C}[\mathrm{i}]$ and $\mathbf{C}[\mathrm{r}]$ (c).

Figure 12 presents the derivative analysis of the antecedent of section a (mm.34-40), considering three superimposed plans: the musical surface (a), and the concrete (b) and abstract levels (c). As it can be observed, the events of the concrete level unfold in a diachronical sequence. On the contrary, the abstract level shows, so to speak, timeless elaborations (albeit a teleological order be always implicit), searching to explain the 
derivations of the concrete material. Four basic Pv's can be identified: $\mathbf{1}$ and $\mathbf{2}$ are overlapped forms, directly derived from Gc A, through intervallic transformation of the original tritone (it is also noteworthy the presence of the abstract variation $b_{2}[r]$ in the rhythmic structure of Pv 2); Pv 3 can be clearly viewed as a concrete transformation of Gc C, but also as subordinate to a more basic form (4), or a "superordinate Pv", resulted from an operation of hybridization considering the rhythmic structures of Gc's B and C. Immediately following Pv 4 there is a case of employment of the linkage technique: ${ }^{8}$ the minor second that closes Pv 4 (B-C) is used (not casually, transposed a tritone upwards: E\#-F\#) to initiate the subsequente fragment, which yields a secondgeneration $\operatorname{Pv}\left(\mathbf{4}_{1}\right)$.

(a)


\footnotetext{
8 Walter Frisch defines linkage: "This technique, by which a "new" Idea evolves spontaneously from a preceding one, is a distinctly Brahmsian one (...)" (FRISCH, 1984, p.15). It is a very interesting fact that this author suggests that Schoenberg has intuitively assimilated this important constructive procedure from analysis of the music of his master Brahms, which can be inferred in a special example inserted in Schoenberg's book on form (SCHOENBERG, 1990, p.65). In this brief excerpt Schoenberg presents an original sentence composed in Brahmsian style (opposed to a classical one) in which there is a clear application of the linkage technique. Frisch considers that the occurrence of linkage in a composition corresponds to an unequivocal evidence of developing variation.
} 
Figure 12: Schoenberg's Op.31: derivative analysis of the antecedent of section a (mm.34-40), considering the musical surface (a), the concrete level (b), and the abstract level (c).

The derivative analysis of the consequent (mm.41-45) is shown in Figure 13. The abstract level presents only two rhythmic transformations of the hybrid $(\mathbf{B}+\mathbf{C})$, properly illustrating the action of DV1. In the concrete level we can observe the presence of four descendant Pv's, of second and third generations $\left(\mathbf{1}_{1}, \mathbf{3}_{1}, \mathbf{4}_{2}\right.$ and $\left.\mathbf{4}_{2.1}\right)$, remotely derived from the respective referential forms. The basic Pv 6 can be interpreted as resulted from the overlapping of these forms. As an alternative (or complementary) analysis for Pv 6, we could consider its rhythmic structure as remotely derived from the combination of Gc's $\mathbf{A}$ and $\mathbf{B}$ (i.e., directly from the Grundgestalt nucleus). It is also noteworthy that the superposition of these variants, intensified at mm.42-43 in a chain-like manner, corresponds to a process of liquidation, ${ }^{9}$ clearly intended to close section $a$ as a sort of substitute for a conventional tonal cadence.

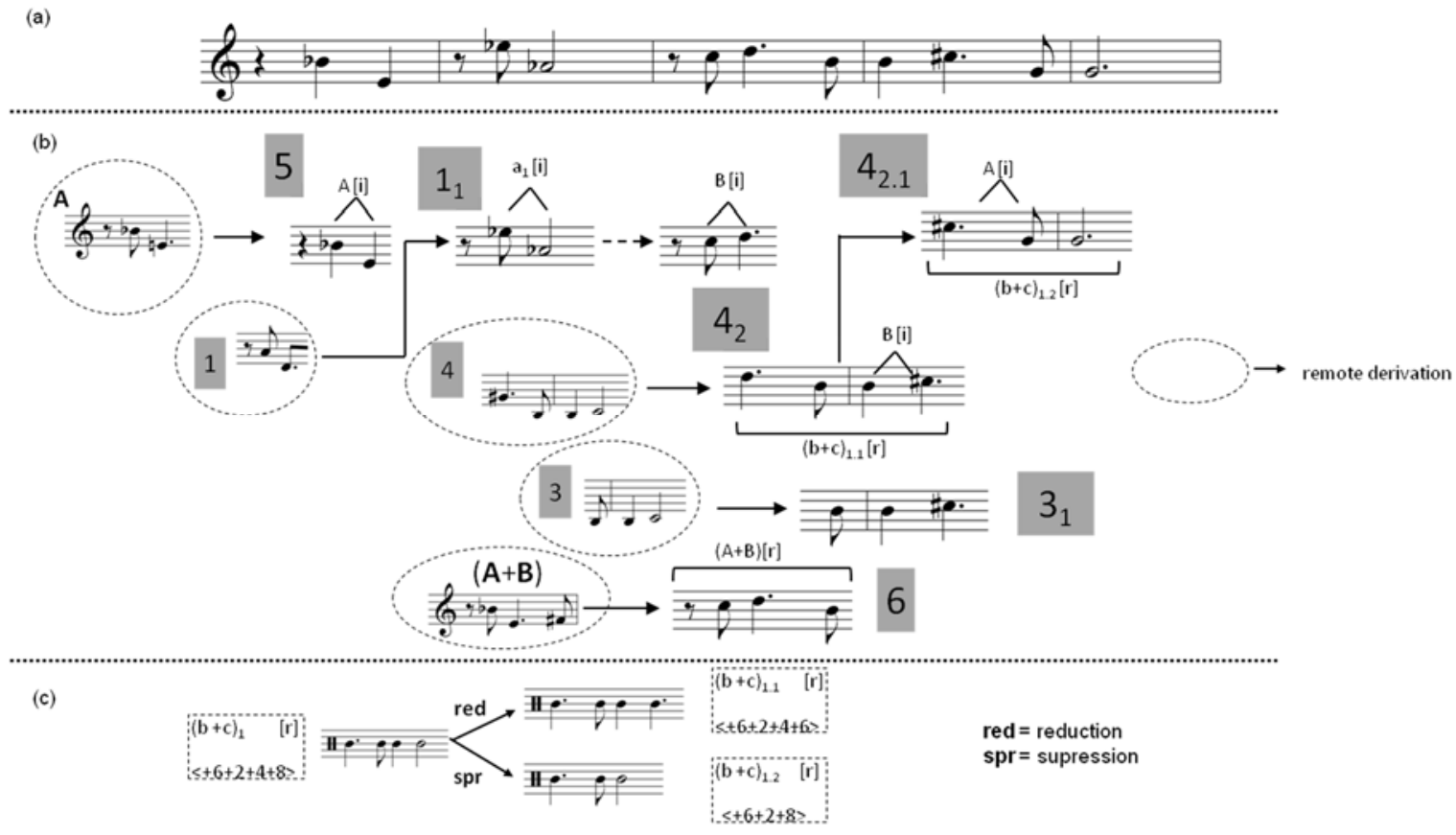

\footnotetext{
${ }^{9}$ According to Schoenberg, "liquidation consists in gradually eliminating characteristic features, until only uncharacteristic ones remain, which no longer demand a continuation (...). In conjunction with a cadence or half cadence, this process can be used to provide adequate delimitation for a sentence." (SCHOENBERG, 1990, p.58)
} 
Figure 13: Schoenberg's Op.31: derivative analysis of the consequent of section $a$ (mm.40-45), considering the musical surface (a), the concrete level (b), and the abstract level (c).

Figure 14 shows the analysis of the contrasting $b$ section. We observe here the presence of only one basic concrete form (7) and four derived Pv's (11.1, 21, $\mathbf{6}_{1}$ and $\mathbf{7}_{1}$ ), which resulted from the intensification of DV2 process and seems to reinforce the intended elaborative function of this passage.

(a)
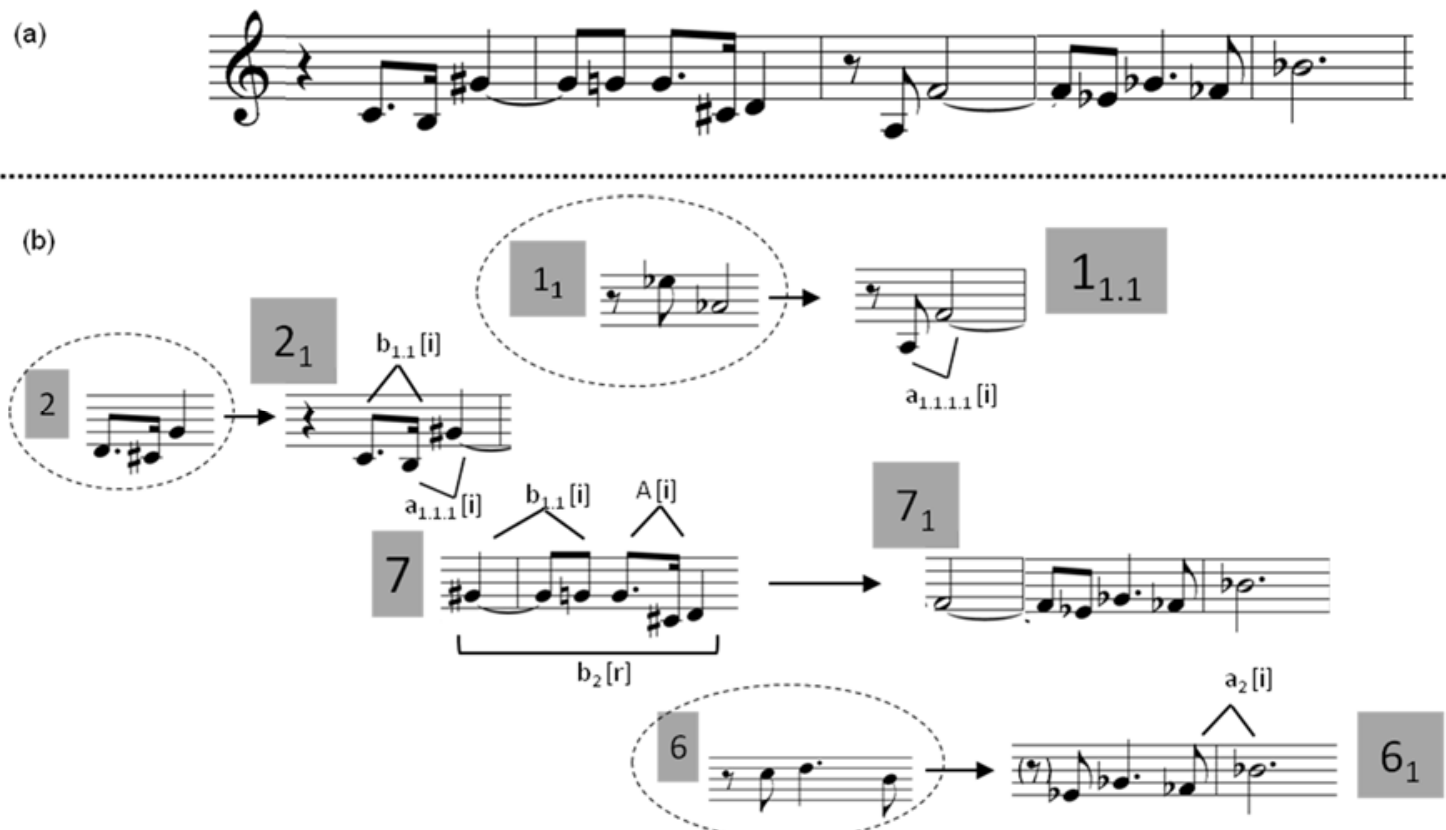

(c)

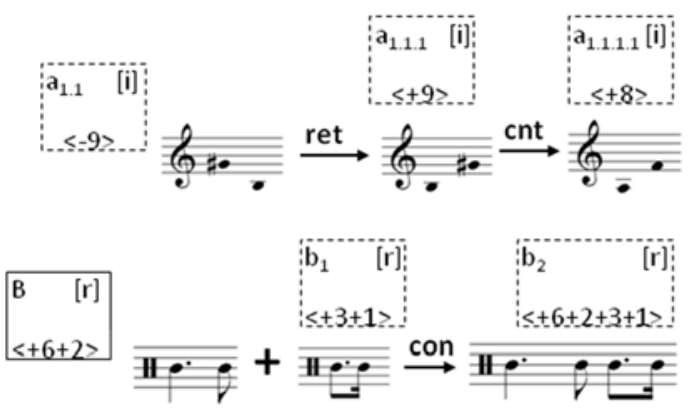

ret $=$ retrogradation

cnt $=$ contraction

con $=$ concatenation

Figure 14: Schoenberg's Op.31: derivative analysis of the section $b$ (mm.46-50), considering the musical surface (a), the concrete level (b), and the abstract level

(c). 
The recapitulative section finalizes the derivative analysis (Figure 15). As previously stated (c.f. Figure 10), since it is used in this passage a transposed and inverted serial form (I-9) in relation to that one employed in the main section (P-0), it is not surprising that the events of mm.46-47 correspond to the exact inversion of the initial bars of the Grundgestalt. However, as shown in Figure 15, an alternative derivation can be proposed, based on another application of the linkage technique. Under this perspective, the fragment employed to conclude the contrasting section ( $\mathrm{Pv} \mathbf{6}_{1}$ ) serves as basis for initiating the recapitulation of the main material (61.1). Another double analytical interpretation can also be proposed for the conclusive segment, both of them ultimately originated from forms of same "family": Pv's $\mathbf{4}$ and $\mathbf{4}_{1}$.

(a)
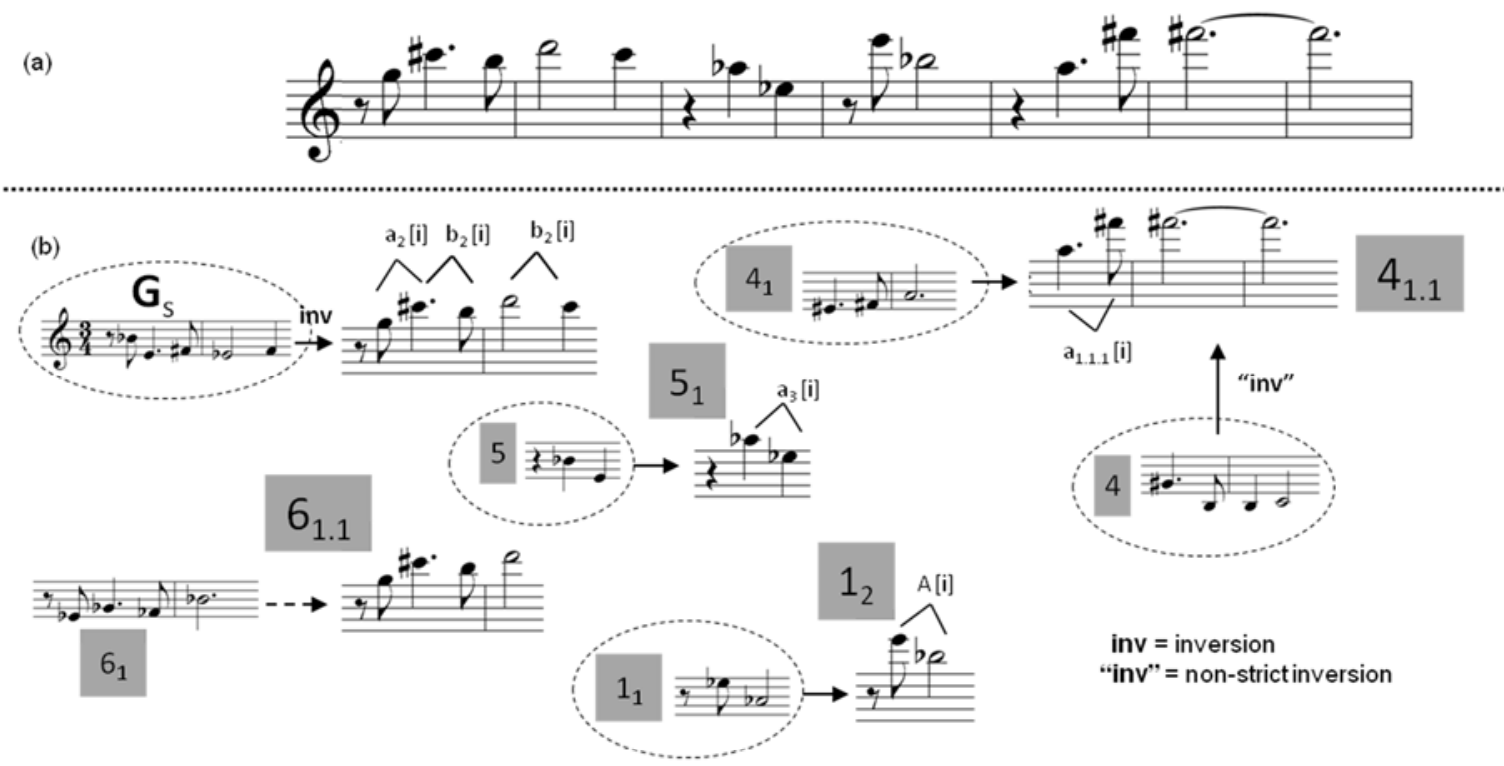

(c)

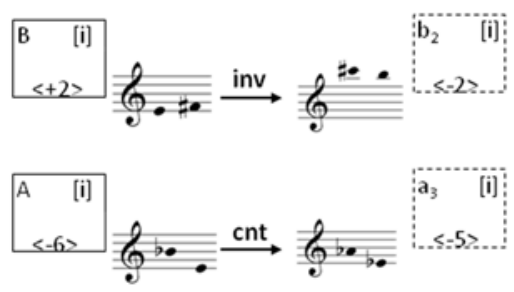

inv $=$ inversion

con $=$ concatenation

Figure 15: Schoenberg's Op.31: derivative analysis of the section $a^{\prime}$ (mm.51-57), considering the musical surface (a), the concrete level (b), and the abstract level

(c). 
Finally, in order to provide a clear overview of the derivative relations involved in the analysis, two genealogical charts were elaborated. Figure 16 presents the lineages of abstract forms produced through developing variation of first order. As can be observed, while some Ga's are considerably prolific, both abstractions from $\mathbf{C}-\mathrm{c}[\mathrm{i}]$ and $\mathrm{c}[\mathrm{r}]$ - are, so to speak, infertile. This is consistent with the considerations previously presented (see p.15), concerning the possible derivation of Gc C from the Grundgestalt's nucleus (A+B).
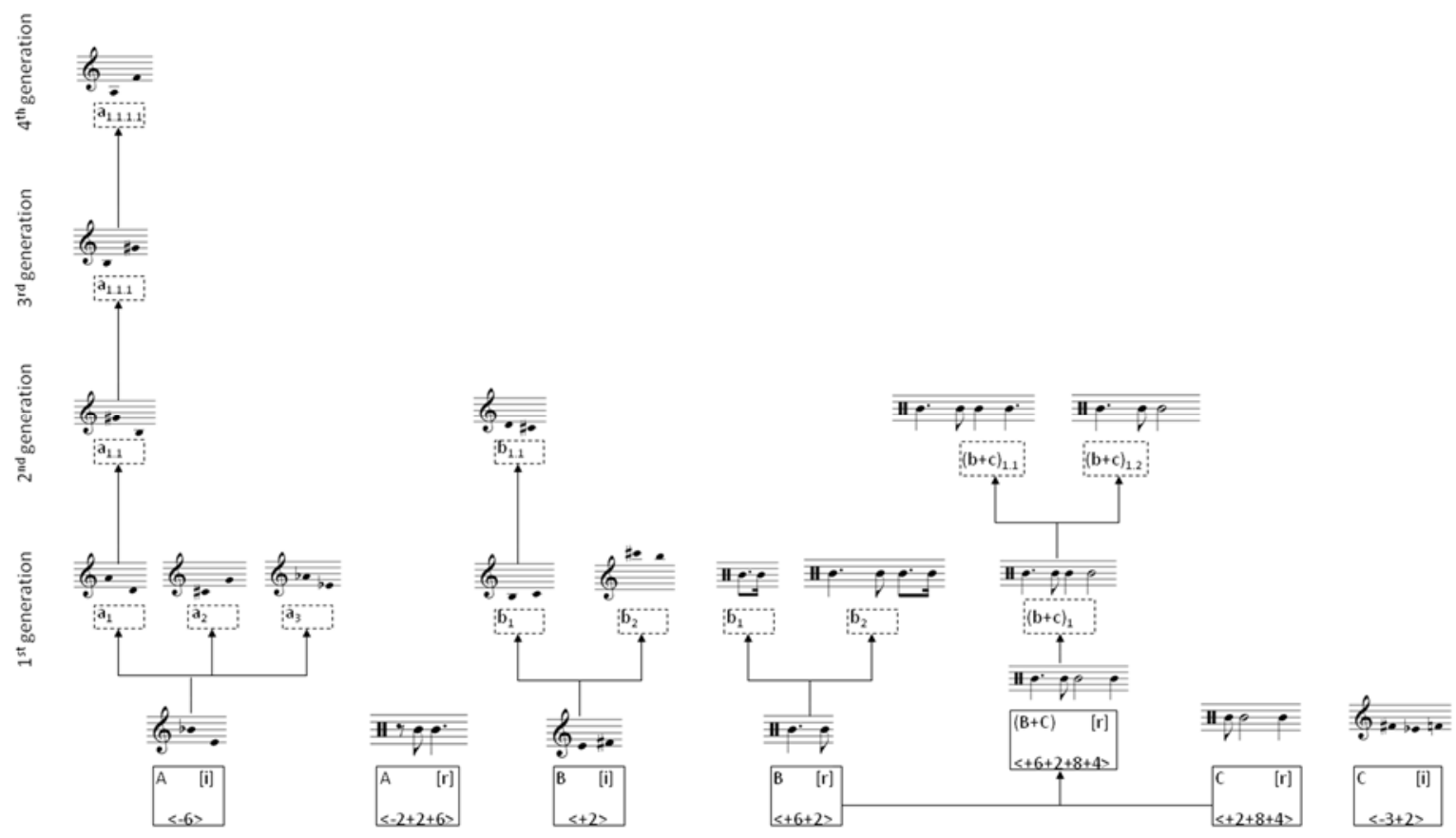

Figure 16: Genealogical tree of the abstract derivative relations in the theme of Schoenberg's Op.31.

The genealogy of the Pv's, obtained through DV2 processes, is shown Figure 17. The scheme reinforces the germinal influence of Gc's $\mathbf{A}$ and $\mathbf{B}$ in comparison with $\mathbf{C}$ : just one of the seven basic Pv's (3) is directly derived from the latter. 


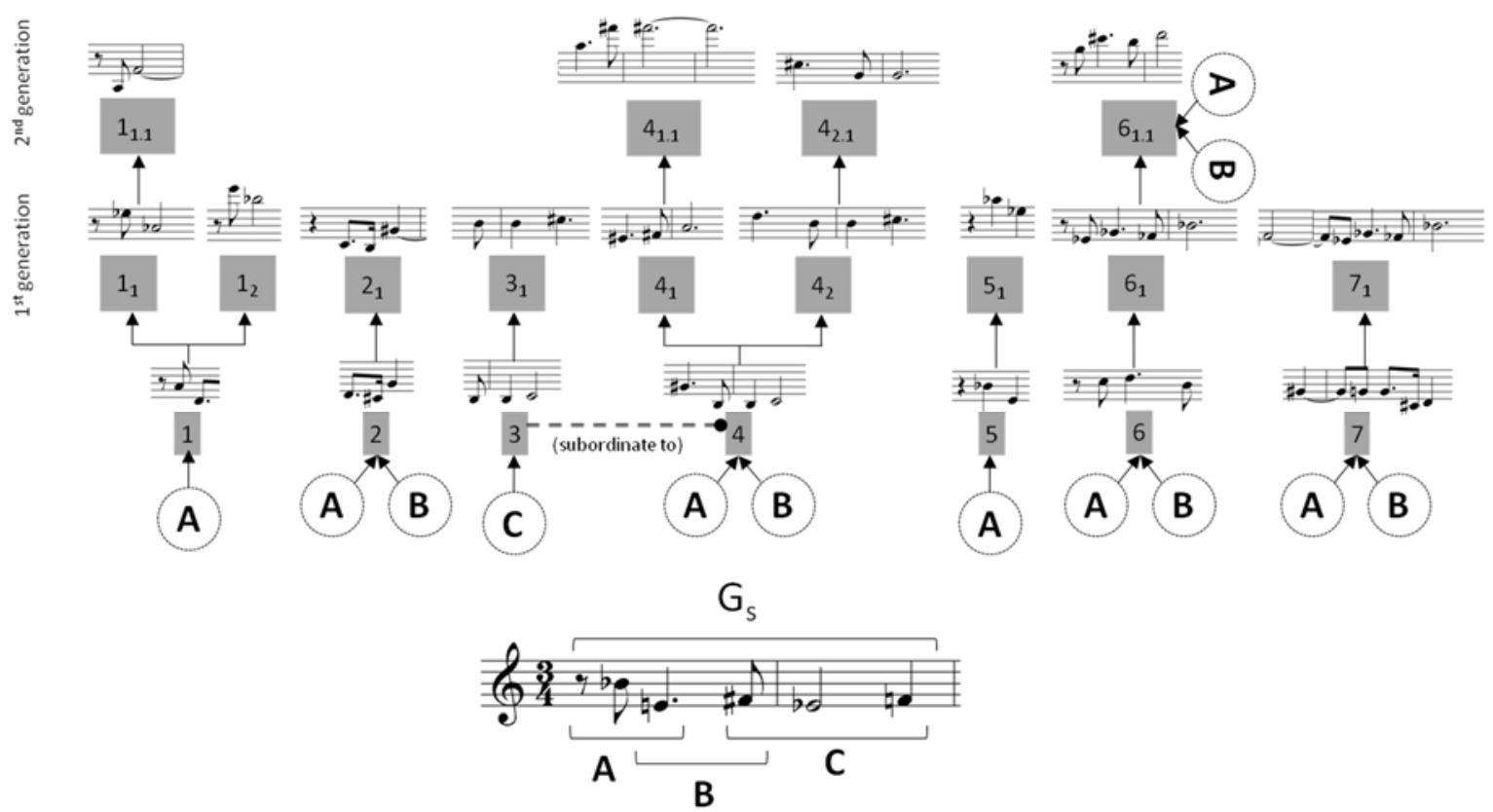

Figure 17: Genealogical tree of the concrete derivative relations in the theme of Schoenberg's Op.31.

\section{5 - Conclusion}

The derivative analysis applied to the Op.31's theme demonstrated Schoenberg's extraordinary capacity for extracting a maximum of material from a minimal group of musical ideas. It is especially noteworthy that the composer, in doing this, showed that he was not at all constrained by the rigid (and, as it is considered by most people, inflexible and "cerebral") twelve-tone postulates. As Schoenberg constantly argued in the defense of this new mode of expression (many times against skeptic ears), he was doing in the serial pieces exactly the same as he did in his tonal phase: simply thematicoriented music. As affirms Ethan Haimo in his analysis of Moses and Aaron, almost exactly contemporary to the Orchestral Variations, in this epoch Schoenberg's serial treatment reached such degree of maturity and sophistication that allowed him to subordinate the manipulation of the row forms to a preferential constructivestructural force: the derivative process, a real trademark of his entire creative career. 
Moreover, this study aimed to propose a new and instigate perspective concerned to the principle of Grundgestalt (not casually elaborated during the formalization of the twelve-tone method), by considering its existence in two distinct levels: one abstract, basic, or idealized, prior to the proper construction of the row; while the other one is concrete, superficial, formed by "real" musical unities, a potential seed for the whole composition, from which most (or even all, as in the present case) of the thematic elements can be derived through gradual and progressive development. The analysis of the $O p .31$ 's theme revealed a perfect integration between its formal, serial and derivative structures, which in turn can be considered as firmly associated to the proposed dual-natured Grundgestalt. Further studies are planned in order to deepen and refine this analytical approach.

\section{References}

1. ALMADA, C. (2009). "Aspectos da construção temática de Arnold Schoenberg a partir de seus escritos teóricos sobre forma”. Per Musi. Belo Horizonte: UFMG. n.20, p.34-43.

2. (2011a). "A variação progressiva aplicada na geração de ideias temáticas". Simpósio Internacional de Musicologia. 2. Rio de Janeiro: UFRJ. p.79-90.

3. (2011b). "A variação progressiva aplicada na geração de ideias temáticas". Encontro Internacional de Teoria e Análise Musical. 2. São Paulo: UNESP-USPUNICAMP. p.10-22.

4. (2013a). "Simbologia e hereditariedade na formação de uma Grundgestalt: a primeira das Quatro Canções Op.2 de Berg”. Per Musi. Belo Horizonte: UFMG. n.27, p.75-88.

5 . (2013b). "Considerações sobre a análise de Grundgestalt aplicada à música popular”. Per Musi. Belo Horizonte: UFMG. n.29, p.117-124.

6. COLLISON, S. (1994). Grundgestalt, developing variation, and motivic processes in the music of Arnold Schoenberg: An analitycal study of the string quartets. Tese (Doutorado em Filosofia) - King's College, Londres, Reino Unido.

7. CONLON, C. (2009). The lessons of Arnold Schoenberg in teaching: The Musikalische Gedanke. Tese (Doutorado em Filosofia) - University of North Texas, EUA.

8. EPSTEIN, D. (1980). Beyond Orpheus: Studies in music structure. Cambridge: The MIT Press. 
9. FRISCH, W. (1984). Brahms and the principle of developing variation. Los Angeles, EUA: University of California Press.

10. (1993). The early works of Arnold Schoenberg (1893-1908). Los Angeles, EUA: University of California Press.

11. HAIMO, E. (1997). “Developing variation and Schoenberg's serial music”. Musical Analysis. v.16, n.3, p.349-365.

12. LEIBOWITZ, R. (1997). Introduction à la musique de douze sons. Paris, França: L'Arche.

13. LEIGH, M. (1998). Grundgestalt, multipiece and intertextuality in Brahms' 0p.117, 118 and 119. Tese (Doutorado em Filosofia) - University of Nottingham, Nottingham, Reino Unido.

14. MEYER, L. (1989). Style and music. Chicago, EUA: University of Chicago Press.

15. RUFER, J. (1954). Composition with twelve notes. Londres, Reino Unido: Rocklife.

16. SCHOENBERG, A. (1929). Variationen für Orchester Op.31. Partitura (78 p.). Orquestra.Viena, Áustria: Universal. Disponível em:

http://imslp.org/wiki/Special:IMSLPDisclaimerAccept/118325 Acesso em: $15 / 1 / 2016$.

17. (1984). Style and idea: selected writings of Arnold Schoenberg. Londres, Reino Unido: Faber \& Faber.

18. (1990). Fundamentals of musical composition. Londres, Reino Unido: Faber \& Faber.

19. TARUSKIN, R. (2010). Music in the early Twentieth Century. Oxford, Reino Unido: Oxford University Press.

Note about the author

Carlos Almada is master and doctor in Music, professor at the School of Music of the University of Rio de Janeiro, composer and arranger. As a scholar, he has published several papers on subjects related to theory and musical analysis, especially concerning the principles of developing variation and Grundgestalt. He is also author of four books adressed to popular music theory: Contraponto em música popular (UFRJ, 2013); Harmonia funcional (UNICAMP, 2009), A estrutura do choro (Da Fonseca, 2006), Arranjo (UNICAMP, 2001). 